\title{
VOOS ATRASADOS E DIREITOS DOS PASSAGEIROS
}

\author{
DELAYED FLIGHTS AND PASSENGERS RIGHTS
}

\section{Thomas Richter \\ Maria Fernanda Monteiro"*}

\begin{abstract}
Resumo:
O artigo busca analisar a tendência de maior proteção aos passageiros aéreos com base no Regulamento n. 261/2004 da União Europeia e o Projeto de Lei n. 6.960/10 no Brasil. O conceito de "atraso" de voos em ambas legislações abarca somente algumas situações o que gera problemas de aplicações práticas. Na Europa o regulamento já foi reinterpretado pelo Tribunal de Justiça da União Europeia para expandir o conceito a outras situações recorrentes por meio de analogia. Apesar disso, ainda há resistência, a High Court do Reino Unido permitiu que as companhias aéreas reenviarem a matéria ao Tribunal de Justiça da União Europeia para reinterpretação, até que isso aconteça os processos estão suspensos. No Brasil, o novo regulamento ainda encontra-se no trâmite legislativo o que permite uma correção para melhoria da lei. Discute-se ainda o possível problema de dupla indenização e o uso de analogia no direito interno e comparado.

Palavras-chave: Analogia. Atraso de voo. Casos Sturgeon e Böck. Companhias aéreas. Indenização. Passageiros aéreos. Projeto de Lei n. 6.960/10 (Brasil). Regulamento n. 261/2004 (UE). Tribunal de Justiça da União Europeia.
\end{abstract}

\begin{abstract}
:
This article intends to analyze the tendency of more protection for flight passengers based on the Regulation n. 261/2004 by the European Union and the brazilian bill n. $6.960 / 10$. In both of these regulations, the concepts for delayed flights just cover some of the situations, that can cause problems on the practical application of the law. In Europe the regulation was already reinterpreted by the Court of Justice of the European Union to expand these concepts to other common situations through analogy. Though there is still resistance: The United Kingdom High Court allowed to the airlines to send the issue back to the Court of Justice of the European Union to be reinterpreted again. This suspends air delay compensation claims. In Brazil, they are still passing through the legislative process which still allows corrections to optimize them. It also discusses the possible issue of double compensations and the use of analogy in internal and international law.
\end{abstract}

Keywords: Airlines. Analogy. Bill n. 6.960/10 (Brazil). Cases Sturgeon and Böck. Compensation. Court of Justice of the European Union. Delayed flights. Passengers. Regulation n. 261/2004 (EU).

Dr. jur. Thomas RICHTER é professor visitante junto à Faculdade de Direito da Universidade de São Paulo e advogado com inscrições em São Paulo e Hamburgo (Alemanha).

• Maria Fernanda Nogueira Ferreira MONTEIRO é graduanda de Direito na Universidade de São Paulo, cursa atualmente o $5^{\circ}$ semestre. maria.fernanda.monteiro@usp.br 
1. Introdução

Cancelamentos, recusas de embarque e atrasos de voos afetam a vida de milhões de pessoas no mundo todo. ${ }^{1} \mathrm{Na}$ União Europeia (II), entrou em vigor em 11 de fevereiro de 2005 o Regulamento n. 261/2004² sobre o direito dos passageiros de avião. Este Regulamento definiu os conceitos de recusa de embarque, cancelamento e atraso, entretanto só prevê expressamente indenização em casos de recusa de embarque e cancelamento. Surgiu, então, o questionamento acerca da utilização de analogia para efeito de indenização em relação aos atrasos. A questão da equiparação foi interpretada positivamente pelo Tribunal de Justiça da União Europeia em novembro de 2009 , decisão esta que deixou dúvidas a serem discutidas no presente artigo. Porém, em agosto de 2010, a High Court do Reino Unido entrou no Tribunal de Justiça da União Europeia com um pedido de reconsideração da interpretação. ${ }^{3}$ Do lado brasileiro (III), seguindo essa tendência internacional de maior proteção aos passageiros, o Ministro da Defesa Nelson Jobim encaminhou ao Congresso Nacional o Projeto de Lei n. 6.960/10 4 de 7 de dezembro de 2009 buscando adequar o Código Brasileiro de Aeronáutica (Lei 7.565/86) ao Código de Defesa do Consumidor (Lei n. 8.078/90). Além disso, já se vê desde julho de 2010 nos aeroportos brasileiros juizados especiais, que visam possibilitar a conciliação entre passageiros e companhias já nos aeroportos.

\section{Direito Europeu}

\subsection{Regulamento n. $261 / 2004$}

O Regulamento n. 261/2004 revogou, em 11 de fevereiro de 2005, o regulamento (CEE) n. 295/91, já que apesar deste, o número de atrasos, cancelamentos e recusa de embarque ainda era considerado demasiado alto. O novo regulamento tem por objetivo elevar o nível de proteção dos passageiros com base na proteção dos consumidores em geral. Aplica-se aos passageiros de voos que partam ou tenham como destino final aeroportos localizados em território dos Estados-membros (art. $3^{\circ}$ ).

$\mathrm{O}$ art. $2^{\circ}$ define os termos utilizados no regulamento, sem, porém, definir "atraso"

\footnotetext{
No ano de 2007, 793 milhões de passageiros pousaram ou decolaram dos aeroportos situados no território da União Europeia, fontes estatísticas do Eurostat.

2 Jornal Oficial da União Europeia n. L 46 de 17 de fevereiro de 2004, p. 1-8.

3 Disponivel em: http://www.bbc.co.uk/news/business-10991631.

4 Disponível em: http://www.camara.gov.br/sileg/MontarIntegra.asp?CodTeor=743397.
} 
$\mathrm{O}$ art. $4^{\circ}$ dispõe sobre a recusa de embarque, situação na qual as companhias devem buscar voluntários que aceitem ceder suas reservas em troca de benefícios. No caso de recusa contra a vontade está previsto indenização nos termos do art. $7^{\circ}$ e assistência nos termos dos art. $8^{\circ}$ e $9^{\circ}$ (alimentação, alojamento, transporte entre a aeroporto e alojamento, possibilidade de comunicação). Consequências estas também previstas nos casos de cancelamentos, art. $5^{\circ}$ admitindo-se exceções: aviso com duas semanas de antecedência, condições extraordinárias ou para avisos com menos de duas semanas com reencaminhamento para outros voos, ${ }^{5}$ recaindo o ônus da prova sobre a empresa.

Já o art. $6^{\circ}$, que dispõe sobre atrasos, objeto do presente artigo, reza:

1. Quando tiver motivos razoáveis para prever que em relação à sua hora programada de partida um voo se vai atrasar:

a. Duas horas ou mais, no caso de quaisquer voos até 1.500 quilómetros;

b. Três horas ou mais, no caso de quaisquer voos intracomunitários com mais de 1.500 quilómetros e no de quaisquer outros voos entre 1.500 e 3.500 quilómetros;

c. Quatro horas ou mais, no caso de quaisquer voos não abrangidos pelas alíneas a) ou b), a transportadora aérea operadora deve oferecer aos passageiros:

i. a assistência especificada na alínea a) do $n .1$ e no n. 2 do art. $9^{\circ}$;

ii. quando a hora de partida razoavelmente prevista for, pelo menos, o dia após a hora de partida previamente anunciada, a assistência especificada nas alíneas b) e c) do n. 1 do art. $9^{\circ}$.

iii. quando o atraso for de, pelo menos, quatro horas, a assistência especificada na alínea a) do $n^{\circ} 1$ do art. $8^{\circ}$.

2. De qualquer modo, a assistência deve ser prestada dentro dos períodos fixados no presente artigo para cada ordem de distância.

\subsection{Estudos empíricos sobre aplicação}

Em 2007, baseado no art. 17 da Regulamentação 261/2004, a companhia de consultaria Steer Davies Gleave, a pedido da Comissão Europeia, publicou um relatório

5 Entre 2 semanas e 7 dias de aviso e reencaminhamento com saída até 2 horas antes e chegada no destino final até 4 horas depois do previsto. Menos de 7 dias de aviso reencaminhamento com saída até 1 hora antes e chegada no destino final até 2 horas depois do previsto. 
sobre os resultados conseguidos pela Regulamentação, 18 meses após sua implantação e com sugestões e recomendações de como aumentar a efetividade. Com base em pesquisas, entrevistas e análise de dados de passageiros, companhias aéreas, órgãos estatais de controle e agências reguladores, o relatório concluiu que os efeitos da Regulação nos casos de atraso, recusa de embarque e cancelamento de voo não foram significativos apesar das intenções dos legisladores.

Os maiores problemas encontram-se na falta de coercitividade das agências reguladoras - falta de imposição de sanções e dificuldade na execução das impostas além disso, verificam-se grandes problemas na interpretação de certos trechos, já que muitos termos não são claros o que abre margem para que as companhias interpretem da maneira que melhor lhes convém, ignorando ou restringindo muitas vezes o direito dos passageiros. Entre os termos não definidos encontram-se passageiro, circunstâncias extraordinárias e atraso.

Em um outro estudo - Eurobarometer ${ }^{6}$ - realizado pela Comissão Europeia entre maio e junho de 2009, verifica-se que além desses problemas há ainda a falta de conhecimento por parte dos passageiros dos seus direitos em grande parte devido à nãoinformação pelas companhias. ${ }^{7}$

\subsection{Casos Sturgeon e Böck}

Dois casos chegaram até o Tribunal de Justiça da União Europeia com os questionamentos a respeito dos atrasos e possíveis indenizações: Sturgeon e Böck.

Em 2005 a família Sturgeon teve seu voo de volta, do Canadá para Alemanha com a empresa Condor, anulado. Após uma pernoite em hotel foi oferecido um voo com outra companhia, chegando assim com 25 horas de atraso em relação à hora prevista do voo não realizado. Entraram com um pedido de indenização de 600 euros por pessoa e indenização suplementar por cancelamento no Amtsgericht Rüsselsheim (Alemanha). A companhia aérea alegou problemas técnicos do avião e doença da tripulação. A primeira decisão constatou atraso e não cancelamento e, portanto, improcedente o pedido de indenização, sentença essa confirmada na segunda instância. Após o pedido de Revision no Bundesgerichtshof houve envio do caso para o TJUE para interpretação dos art. $2^{\circ}$, alínea ' 1 ', e $5^{\circ}$, n. 1, alínea 'c' do Regulamento n. 261/2004. ${ }^{8}$

\footnotetext{
6 Special Eurobarometer 319 "Air Passengers" rights".

7 Verifica-se que quase 6 entre 10 europeus não conhecem seus direitos e obrigações contratuais e apenas $23 \%$ destes sabiam dos novos direitos vindos do Regulamento n. 261/2004. Quanto a serem informados, apenas $20 \%$ dos passageiros afirmam terem visto nos aeroportos uma lista de seus direitos, por outro lado pouco mais da metade $(51 \%)$ dos europeus afirmam terem recebido alguma informação das companhias aéreas.

8 Processo C-402/07.
} 
O segundo caso se desenrolou de maneira bastante parecida. S. Böck e C. Lepuschitz após uma notificação de anulação e oferta de voo alternativo chegaram no destino com mais de 22 horas de atraso em relação a hora prevista pelo voo não realizado. A empresa Air France alegou defeito técnico e necessidade de descanso da tripulação. Após o processo interno na Áustria houve o envio do processo ao TJUE. ${ }^{9}$

\subsection{Decisão prejudicial do Tribunal de Justiça da União Europeia}

Os processos Sturgeon e Böck chegaram ao Tribunal de Justiça da União Europeia com base no art. $267^{10}$ do Tratado da União Europeia. A partir da alínea 'b' deste artigo verifica-se que o TJUE tem competência para decidir de maneira vinculante sobre a interpretação do Direito Europeu, tal como o Regulamento n. 261/2004, já que este é um ato de direito comunitário secundário. As decisões prejudiciais do TJUE dizem respeito apenas à interpretação do Direito Europeu, permanecendo a decisão do mérito tarefa do tribunal de origem. Nos casos em tela, o TJUE apensou os dois processos para decisão conjunta, e entendeu as questões prejudiciais no sentido que segue:

a. Um atraso de um voo deve ser considerado um cancelamento, quando o atraso seja considerável?

b. Os passageiros de voos atrasados podem ser equiparados aos passageiros de voos cancelados, para efeitos de indenização?

c. Problema técnico é circunstância extraordinária?"'1

a) Definição de atraso e cancelamento

No regulamento falta a definição expressa do conceito "atraso de voo" 12 O TJUE constata que a partir do art. $6^{\circ}$ pode-se extrair uma definição que leva em conta,

$9 \quad$ Processo C-432/07.

10 Ex-art. 234 TCE: "O Tribunal de Justiça da União Europeia é competente para decidir, a título prejudicial: a) Sobre a interpretação dos Tratados;

b) Sobre a validade e a interpretação dos actos adoptados pelas instituições, órgãos ou organismos da União. Sempre que uma questão desta natureza seja suscitada perante qualquer órgão jurisdicional de um dos Estados-Membros, esse órgão pode, se considerar que uma decisão sobre essa questão é necessária ao julgamento da causa, pedir ao Tribunal que sobre ela se pronuncie. Sempre que uma questão desta natureza seja suscitada em processo pendente perante um órgão jurisdicional nacional cujas decisões não sejam susceptiveis de recurso judicial previsto no direito interno, esse órgão é obrigado a submeter a questão ao Tribunal. Se uma questão desta natureza for suscitada em processo pendente perante um órgão jurisdicional nacional relativamente a uma pessoa que se encontre detida, o Tribunal pronunciar-se-á com a maior brevidade possível."

11 Acórdão do Tribunal de Justiça de 19 de novembro de 2009, C-402/07 e C-432/07.

12 TJUE, 19/11/2009 (NR 12), § 29. 
porém, a hora de partida inicialmente prevista, mas não a perda de tempo realmente dita. ${ }^{13}$ Não definiria que necessariamente estejam presentes os mesmos passageiros, caso siga o mesmo itinerário. ${ }^{14}$ Já o cancelamento enquadrar-se-ia em uma categoria distinta, com base no art. $2^{\circ}$, deve haver uma programação diferente da inicial para que se configure o cancelamento, o que não ocorreu nos casos Sturgeon e Böck. Assim não seria possível qualificar atraso considerável como cancelamento. ${ }^{15}$ Voo atrasado não seria considerado cancelado independente do tempo de atraso se seguir o itinerário original.

O TJUE, considerando as situações descritas no art. $6^{\circ}$ como definição de atraso, foi além do necessário para responder a questão colocada. O TJUE apenas devia esclarecer se um voo atrasado no sentido do art. $6^{\circ}$ como nos casos Sturgeon e Böck, pode ser considerado cancelamento, sem necessidadae de delimitar o termo "atraso". Delimitando o termo "atraso", o TJUE não levou em conta que o art. $6^{\circ}$ não define o termo, e nem precisa defini-lo. Sendo sua consequência jurídica o formecimento de assistência no aeroporto de saída, art. $6^{\circ}$ apenas descreve, no suporte fático, os tipos de atraso que provocam a obrigação da companhia aérea para oferecer tal assistência. Para esse fim,o critério do tempo de atraso previsto mede-se pela hora programada de partida. Ora, não se pode concluir, ainda, que o legislador queria definir atraso em geral, de maneira que voos que saem na hora de partida programada mas chegam mais de quatro horas após a hora de chegada programada, considerar-se-iam como não atrasados. A definição não devida tem relevância não para os casos em tela, mas para o tratamento de "atrasos" que não se encaixarem nos atrasos referidos pelo art. $6^{\circ}$ como, por exemplo, voos que saem pontualmente, mas atrasam no caminho, devido a problemas técnicos. A definicao não devida, ainda, opõe-se à definição legal no art. $3^{\circ}$ alínea 12 do Regulamento relativo aos direitos e obrigações dos passageiros dos serviços ferroviários ${ }^{16}$ que reza:

12. «Atraso», a diferença horária entre a hora a que o passageiro deveria chegar de acordo com o horário publicado e a hora real ou prevista da sua chegada;

b) Equiparação de atraso a cancelamento para efeitos de indenização

Em sua decisão afirmou o TJUE que o art. $5 .^{\circ}$ do regulamento em questão prevê apenas indenização por cancelamento, não por atraso. Ora, a interpretação do mesmo

\footnotetext{
TJUE, 19/ 11/2009 (NR 12), §§ 31, 32.

4 TJUE, 19/11/2009 (NR 12), §§ 34, 35, 38.

15 TJUE, 19/11/2009 (NR 12), § 39.

16 Regulamento (CE) n. 1371/2007 do Parlamento Europeu e do Conselho de 23 de Outubro de 2007 relativo aos direitos e obrigações dos passageiros dos serviços ferroviários.
} 
deve levar em conta o contexto no qual foi escrita a norma e os objetivos do legislador. ${ }^{17}$ Em mais de uma passagem do texto o legislador relaciona atrasos com indenização, como no considerando 15 , que define circunstâncias extraordinárias em relação a atraso considerável e cancelamento, e circunstância extraordinária é excecão ao art. $5^{\circ}$, que regula indenizações. ${ }^{18}$

Reitera o Tribunal que buscando os objetivos do legislador, verifica-se nos considerandos 1 e 2 do Regulamento a busca de uma maior proteção dos passageiros nos casos de recusa de embarque, de cancelamento ou de atraso do voo, já que todos causam transtornos e inconvenientes aos passageiros. Sendo assim, deve se buscar reparar igualitariamente os prejuízos, baseado no princípio da igualdade de tratamento (situações comparáveis de maneira igual). Faz-se necessária uma interpretação ampla, ou seja, aquela que mantém o efeito útil do dispositivo. ${ }^{19}$ No caso específico há uma comparação do tipo e importância dos inconvenientes e prejuízos sofridos. Como o tempo perdido é irreversível, tanto em casos de cancelamento como de atrasos, há prejuízo análogo, em alguns casos havendo até menor perda de tempo no cancelamento, é necessária para reparação uma indenização baseada no tempo perdido e não no motivo deste (cancelamento ou atraso). ${ }^{20}$

Considera o TJUE que o art. $5^{\circ}$, n. 1, alínea 'c', 'iii', garante indenização a cancelamento que gere perda de tempo de 3 horas ao passageiro, caso não haja equiparação para voos que cheguem ao seu destino com 3 horas ou mais de atraso há uma quebra do princípio da igualdade de tratamento, tratamento menos favorável para situação igual. ${ }^{21}$

Enfim, o TJUE precisa que o montante da indenização devida a um passageiro nos termos do art. $7^{\circ}$ n. 1 pode ser reduzido por $50 \%$ nos casos previstos no art. $7^{\circ}$ n. 2. Resulta que o montante de indenização devida a um passageiro de um voo atrasado, que chega ao seu destino final três horas ou mais após a hora de chegada inicialmente prevista, pode ser reduzido $50 \%$, em conformidade com o art. $7^{\circ}$ par. $2^{\circ}$ alínea ' $c$ ' quando o atraso for inferior a quatro horas e se tratar de voos extracomunitários com mais de 3.500 quilometros.

A arguição do TJUE convence na medida em que ela toma como base da analogia o princípio da igualdade e a vinculação de atraso considerável ao direito à indenização. O critério do tempo perdido convence frente ao fortalecimento da proteção de todos os passageiros aéreos como objetivo da norma. ${ }^{22}$ Porém, o TJUE parece ter aberto, erroneamente, a analogia para passageiros cujos voos chegaram ao seu destino

\footnotetext{
17 TJUE, 19/11/2009 (NR 12), §41.

18 TJUE, $19 / 11 / 2009$ (NR 12), § 43.

19 TJUE, 19/11/2009 (NR 12), §§ 44, 45, 47, 48

20 TJUE, 19/11/2009 (NR 12), §§52, 53, 54.

21 TJUE, 19/11/2009 (NR 12), §§ 57, 58, 60, 61.

22 TJUE, $19 / 11 / 2009$ (NR 12), $\$ \S 60$.
} 
"com 3 horas ou mais de atraso" e não apenas para passageiros cujos voos chegaram "com mais de três horas de atraso" $\mathrm{O}$ art. $5^{\circ}$, par. $1^{\circ}$ alínea 'c' 'iii' exclui a indenização se aos passageiros "tiver sido oferecido reencaminhamento que lhes permitisse partir até uma hora antes da hora programada de partida e chegar ao destino final até duas horas depois da hora programada de chegada." Conclui-se que sempre cabe indenização quando o atraso for maior de 3 horas. Somente nesta medida teria cabido ao TJUE aplicar a analogia a favor de passageiros de voos atrasados. O próprio TJUE aplica a analogia de maneira correta, quando avisa acerca da redução da indenização por $50 \%$, nos casos do art. $7^{\circ}$ par. $2^{\circ}$ : ele exclui uma redução para os casos do art. $7^{\circ}$ par. $2^{\circ}$ alíneas ' $a$ ' e ' $b$ ', totalmente, embora alínea ' $b$ ' conteria o caso de uma chegada atrasada de exatamente três horas. Infelizmente, o cálculo errôneo ainda chegou a ser inserido no teor da sentença. ${ }^{23}$

Cabe, ainda, ressaltar o problema da definição de "atraso" O TJUE aplica a analogia apenas a passageiros de voos "atrasados" nas moldes do art. $6^{\circ}$ do Regulamento. Este obiter dictum delimita a analogia aos casos de atraso mencionados no art. $6^{\circ}$ do Regulamento. Coloca-se a questão se um caso de saída pontual com chegada atrasada por 30 horas (por exemplo, devido a um problema técnico ocorrido no caminho) não deveria se equiparar, para fins de indenização, a um caso com saída e chegada atrasadas por três horas e meia. Os argumentos utilizidos pelo próprio TJUE parecem favorecer tal equiparação. Seria uma dupla analogia, porém uma consequente.

c) Problema técnico como circunstância extraordinária

Como nos casos em tela, as companhias aéreas alegaram avarias técnicas e doença da tripulação, o TJUE teve que responder à questão prejudicial se um problema técnico em uma aeronave é abrangido pelo conceito de "circunstâncias extraordinárias" Tal questão já foi decidida previamente pelo Tribunal: ${ }^{24} \mathrm{O}$ art. $5^{\circ}, \mathrm{n} .{ }^{\circ} 3$, do Regulamento deve ser interpretado no sentido de que problema técnico não configura circunstâncias extraordinárias, exceto se decorrer de eventos não inerentes ao exercício normal da atividade da transportadora aérea ou escaparem ao seu controle efetivo. ${ }^{25} \mathrm{O}$ TJU aplica então a teoria da esfera: Se o risco se realizou na esfera de controle da companhia aérea, ela carrega o ônus de provar que o risco não era por ela controlável. Via de regra, especialmente nos casos de problemas técnicos, esta prova é difícil de se realizar. Um exemplo de problema técnico não previsto mas inerente à esfera de controle da companhia aérea seria um problema nos pneus, já o ocorrido com vulcão islândes Eyjafjallajokull em abril de 2010 caracateriza uma circunstância extraordinária, fora de seu controle.

\footnotetext{
23 TJUE, 19/11/2009 (NR 12), após § 73.

24 Acordão do Tribunal de Justiça de 22 de dezembro de 2008, Processo C-549/07.

25 TJUE, 19/11/2009 (NR 12), § 70, 72.
} 


\subsection{Situação atual}

Em 18 de fevereiro de 2010, o Bundesgerichtshof $(B G H)^{26}$ decidiu no mérito conforme interpretação do TJUE. Face ao atraso superior a três horas o BGH concedeu indenização a todos os autores.

Em 17 de agosto de 2010 a High Court ${ }^{27}$ do Reino Unido retornou a matéria ao TJUE pedindo uma revisão em relação à posição do Tribunal acerca dos atrasos. A High Court atuou a pedido das companhias aéreas do Reindo Unido, que não possuem recurso formal. Um novo julgamento do TJUE não deverá acontecer até meados de 2012. Segundo a High Court, os tribunais do Reino Unido deixarão de julgar casos que versem sobre a matéria até decisão do T兀E. ${ }^{28}$

Uma nova proposta de regulamentação sobre direitos dos passageiros foi aprovada no Parlamento Europeu em fevereiro de 2011. O Regulamento deverá vigorar a partir de 2013 e iguala os direitos dos passageiros de ônibus em viagens com mais de $250 \mathrm{~km}$ aos direitos dos passageiros aéreos, de navio ou trens. Essa equiparação reforça a busca mundial de maior proteção aos transportados.

\section{Direito brasileiro}

\subsection{Projeto de Lei n. $6.960 / 10$}

O Projeto de Lei n. 6.960/10, ${ }^{29}$ proposto pelo Ministro da Defesa Nelson Jobim, altera e acresce dispositivos à lei n. 7.565/86, Código Brasileiro de Aeronáutica. Visa regular voos partindo do Brasil e estabelece os direitos dos passageiros e deveres das companhias nos casos de cancelamento, recusa de embarque ou atraso superior a 2 horas na partida. ${ }^{30}$ Além do âmbito e das possibilidades de aplicação, o art. 229 também estabelece em seus incisos o que poderá ser oferecido alternativamente aos passageiros, e em seu inciso IV estabelece o reembolso do valor do bilhete. $\mathrm{Na}$ ocorrência das hipóteses previstas no art. 229, além do reembolso do valor do bilhete, o passageiro também terá direito a indenização de $50 \%$ do valor do bilhete (art. 230). Vigem as seguintes exceções: aviso prévio de mais de 7 dias; caso fortuito, força maior ou exercício regular do poder de polícia ou a possibilidade de voo alternativo com saída até duas horas antes e chegada até duas horas depois do previsto. Há ainda nesse projeto de lei, a regulamentação da

\footnotetext{
26 Bundesgerichtshof (Tribunal Superior Alemão), decisão de 18 de fevereiro de 2010, caso Xa ZR 95/06..

27 Suprema Corte do Reino Unido.

28 Disponivel em: http:/www.brightonwired.co.uk/news.php/86353-Airline-compensation-claims-scuppered.

29 Disponível na íntegra em: http:/www.camara.gov.br/sileg/integras/743397.pdf.

30 Art. 229 do Código Brasileiro de Aeronáutica alterado.
} 
assistência devida aos passageiros e institui-se o dever de informação das companhias aéreas. A regulamentação da aplicação fica a cargo do Executivo. ${ }^{31}$

Apesar da influência europeia o regulamento brasileiro é mais rígido em um ponto ao prever indenizações já a partir de duas horas de atraso na saída. Essa delimitação não define porém o conceito de atraso, incorrendo no mesmo problema do regulamento europeu. Cria-se uma categoria de atraso que exclui porém várias outras situações que acarretam perda de tempo e incovenientes e prejuízos aos passageiros. Por exemplo, o regulamento deixa em aberto a questão do atraso no horário de chegada. Um voo que saia no horário previsto mas chegue algumas horas depois do previsto não ensejaria indenização na nova lei brasileira. Uma ocorrência desse tipo também deveria receber proteção nessa mudança do texto legal, já que a própria Exposição de Motivos do Projeto de Lei alega uma busca por maior proteção aos passageiros.

Outro caso que não aparece no texto legal são os voos que chegam no Brasil e sofreram qualquer uma das situações listadas no art. 229. Esse âmbito reduzido não corresponde à proteção dada no Regulamento Europeu, já que este em seu art. $3^{\circ}$ dispõe sobre a aplicação tanto para voos que partem quanto para os que chegam em um aeroporto localizado na União Europeia. A ausência de previsão dessas duas situações é um problema cuja discussão anterior à promulgação da lei pode evitar questionamentos posteriores como o que ocorreu com o regulamento europeu. Essa lacuna da lei pode levar a aplicações díspares nos tribunais e encontra fundamento no Direito Comparado, respectivamente jurisprudência e legislação, para aplicação de analogia com os casos de atraso na saída ou voos com destino ao Brasil.

Questiona-se ainda o disposto no art. 230, que prevê indenização com base no valor do bilhete, outra disposição diferente ao Regulamento Europeu. A indenização prevê uma reparação pelos inconvenientes causados pelas situações de cancelamento, recusa de embarque e atrasos. Ora, tais inconvenientes independem na maior parte dos casos do valor do bilhete. Uma quantia fixa com base em critérios objetivos, como distância e tempo, parece mais adequado aos objetivos da lei de proteção aos passageiros. Além disso, o critério 'valor' abre margem para questionamentos práticos em relação ao critério 'preço' a bilhetes de ida e volta e a bilhetes adquiridos em promoções. Pelo outro lado, a referência ao preço é praxe européia no caso de atrasos de trens ${ }^{32}$ e consta no projeto já aprovado de indenização no caso de atrasos de ônibus. ${ }^{3.3}$

\footnotetext{
31 Art. $5^{\circ}$, PL $6.960 / 10$.

32 Art. $17 \S 1^{\circ}$ do Regulamento (CE) n. 1371/2007 do Parlamento Europeu e do Conselho de 23 de Outubro de 2007 relativo aos direitos e obrigações dos passageiros dos serviços ferroviários.

33 Art. 20 da Proposta de Regulamento do Parlamento Europeu e do Conselho respeitante aos direitos dos passageiros no transporte de autocarro e que altera o Regulamento (CE) n. 2006/2004 relativo à cooperação entre as autoridades nacionais responsáveis pela aplicação da legislação de defesa do consumidor.
} 


\subsection{Juizados Especiais}

Antes mesmo da aprovação do projeto de lei já se vê nos aeroportos brasileiros uma modificação no que diz respeito às relações entre companhias aéreas e passageiros. Desde 23 de julho de 2010 juizados especiais estão funcionando nos aeroportos do Galeão e Santos Dumont, no Rio de Janeiro, Congonhas e Guarulhos, em São Paulo, e Juscelino Kubitschek, em Brasília. Nesse juizados diante da presença de um mediador da Justiça as partes tentam chegar a um acordo, caso não haja, o autor pode entrar com um pedido de ação ali mesmo (caso o valor da causa seja de até 40 salários mínimos). Tais juizados podem facilitar a aplicação da nova lei caso essa seja aprovada no Congresso.

\section{Dupla indenização}

Tendo estudado as normativas europeia e brasileira, coloca-se a questão se, em casos trans-fronteiriços, cabe indenização tanto pela jurisdição e pelo direito do país de partida quanto pela jurisdição e pelo direito do país de chegada. O problema é de dupla natureza.

Em primeiro lugar, cabe verificar se pode haver duas (ou mais) jurisdições competentes. O direito europeu determina a competência intenracional em relação a serviços no art. $5^{\circ} \S 1^{\circ}$ alínea b) do Regulamento Bruxelas I: $3^{34}$

Uma pessoa com domicílio no território de um Estado-
Membro pode ser demandada noutro Estado-Membro: [...]
Para efeitos da presente disposição e salvo convenção em
contrário, o lugar de cumprimento da obrigação em questão
será:[...] no caso da prestação de serviços, o lugar num
Estado-Membro onde, nos termos do contrato, os serviços
foram ou devam ser prestados;

Colocava-se a questão de qual é o lugar no qual um voo se presta, no lugar de saída, naquele de chegada (prevista), em ambos lugares ou em um outro lugar, como a sede social da linha aérea. Recentemente o Tribunal Europeu teve que decidir a questão no caso Peter Rehder ./. Air Baltic Corporation. O passageiro Rehder teve seu voo de Munique a Vilnius anulado, e buscou indenização perante o tribunal de primeira instância de Erding, em cuja comarca situa-se o aeroporto de Munique. O Amtsgericht Erding, tribunal de primeira instância, assumiu sua competência a partir do art. art. $5^{\circ} \S$ $1^{\circ}$ alínea b) da Convenção de Bruxelas I, concluindo que a prestação começa no lugar de saída. Após apelação pela Air Baltic Corporation o Oberlandesgericht München negou tal

34 Regulamento (CE) n. 44/2001 do Conselho de 22 de Dezembro de 2000 relativo à competência judiciária, ao reconhecimento e à execução de decisões em matéria civil e comercial. 
competência, argumentando que a prestação se dava unicamente a partir da sede social da companhia aérea. Ora, o Bundesgerichtshof, em processo de revisão, enviou o caso ao TJUE para interpretação prejudicial. O TJUE, enfim, decidiu em favor do posicionamento da primeira instância, no sentido de que em caso de transporte aéreo de pessoas de um Estado-Membro com destino a outro Estado-Membro, realizado com base num contrato celebrado com uma única companhia aérea que é a transportadora operadora, o tribunal competente para conhecer de um pedido de indenização é aquele, à escolha do requerente, em cujo foro se situa o lugar de partida ou o lugar de chegada do avião, tal como esses lugares são estipulados no referido contrato. ${ }^{35}$

Conclue-se que os tribunais europeus têm competência internacional para todo voo atrasado tenha a União Europeia como procedência ou destino. Quanto ao direito aplicável, as normas europeias

de proteção ao passageiro são de aplicação imediata, nos termos do art. $3^{\circ}$, art. $5^{\circ} \S 2^{\circ}$ e art. $9^{\circ}$ do Regulamento Roma I. ${ }^{36}$

Pode ocorrer, então, que o mesmo atraso cria uma dupla competência internacional com a aplicação de direitos diferentes. Por exemplo, a indenização de atraso um voo direto de São Paulo a Munique pode ser julgada tanto perante os tribunais alemães, aplicando as normas europeias, quanto perante os tribunais brasileiros, aplicando as normas brasileiras. Cabe às partes e aos advogados envolvidos ponderar cuidadosamente as vantagens de cada jurisdição frente aos interesses dos clientes e da exigüibilidade.

\section{Conclusão}

Apesar dessa nova tendência mundial de busca por maior proteção dos passageiros aéreos os legisladores e aplicadores do Direito devem estar atentos às falhas nos textos legais que deixam diversas situações em aberto. Tais situações complicam a vida dos passageiros que buscam por indenização e assistência quando sofrem com atrasos, cancelamentos e recusas de embarque. Faz-se necessária a busca de conceito amplo e objetivo com base na perda de tempo para otimizar a aplicação das leis nos casos práticos.

A experiência atual mostra que na lacuna da lei o uso da analogia no direito interno e internacional ajuda a resolver tais problemas porém prolongando o processo judiciário e o recebimento das indenizações. Assim, uma modificação do projeto de lei no Brasil pode evitar futuros problemas com a aprovação da lei e seu uso efetivo.

São Paulo, dezembro de 2010.

35 TЛUЕ, 9/7/2009, C-204/08, § 48 .

${ }_{36}$ Regulamento (CE) n. 593/2008 do Parlamento Europeu e do Conselho de 17 de Junho de 2008 sobre a lei aplicável às obrigações contratuais (Roma I). 


\section{Referências}

AIRLINE compensation claims scuppered. Brightonwired. 31 ago. 2010. Disponível em: <http:// www.brightonwired.co.uk/news.php/86353-Airline-compensation-claims-scuppered $>$. Acesso em: 28 out. 2010 .

ALEMANHA. Bundesgerichtshof. Xa ZR 95/06. Entscheidungen. Karlsruhe, Alemanha, 18 fev. 2010. Disponivel em: <http://juris.bundesgerichtshof.de/cgi-bin/rechtsprechung/document.py?Ger $i c h t=b g h \& A r t=e n \& n r=51293 \&$ pos $=0 \& a n z=1>$. Acesso em: 20 set. 2010.

BRASIL. Projeto de Lei 6.960/10. Poder Legislativo, Brasília, DF, 7 dez. 2009. Disponível em: $<$ http://www.camara.gov.br/sileg/integras/743397.pdf>. Acesso em: 18 set. 2010.

EUROPA. Proposta de Regulamento do Parlamento Europeu e do Conselho respeitante aos direitos dos passageiros no transporte de autocarro e que altera o Regulamento (CE) n. 2006/2004 relativo à cooperação entre as autoridades nacionais responsáveis pela aplicação da legislação de defesa do consumidor; COM (2008) 817 final. Decisão do Comité Conciliação. 30 nov. 2010. Disponível em: $<$ http://ec.europa.eu/prelex/detail_dossier_real.cfm?CL=pt\&DosId=197709>. Acesso em: 10 jan. 2011.

EUROPA. Regulamento (CE) n. 1.371/2007 do Parlamento Europeu e do Conselho de 23 de Outubro de 2007 relativo aos direitos e obrigações dos passageiros dos serviços ferroviários. Jornal Oficial da União Européia, n. L 315, p. 14, 3 dez. 2007.

EUROPA. Regulamento (CE) n. 261/2004 do Parlamento Europeu e do Conselho de 11 de Fevereiro de 2004 que estabelece regras comuns para a indemnização e a assistência aos passageiros dos transportes aéreos em caso de recusa de embarque e de cancelamento ou atraso considerável dos voos e que revoga o Regulamento (CEE) n. 295/91. Jornal Oficial da União Européia, n. L 46, p. $1-8,17$ fev. 2004.

EUROPA. Regulamento (CE) n. 593/2008 do Parlamento Europeu e do Conselho de 17 de Junho de 2008 sobre a lei aplicável às obrigações contratuais (Roma I). Jornal Oficial da União Européia, n. L 177, p. 6-16, 4 jul. 2008.

EUROPA. Regulamento n. 44/2001 do Conselho de 22 de Dezembro de 2000 relativo à competência judiciária, ao reconhecimento e à execução de decisões em matéria civil e comercial. Jornal Oficial das Comunidades Européias, n. L 12, p., 16 jan. 2001.

EUROPA. Tribunal de Justiça da União Europeia (Quarta Seção). Acórdão do processo C-204/08. Peter Rheder contra Airbaltic Corporation. Colectânea da Jurisprudência 2009, p. I-06073. Luxemburgo, 9 jul. 2009.

EUROPA. Tribunal de Justiça da União Europeia (Quarta Seção). Acórdão do processo C-549/07. Friederike Wallentin-Hermann contra Alitalia - Linee Aeree Italiane SpA. Colectânea da Jurisprudência 2008, p. I-11061. Luxemburgo, 22 dez. 2008. 
EUROPA. Tribunal de Justiça da União Europeia (Quarta Seção). Acórdão dos processos apensos C-402/07 e 432/07. Christopher Sturgeon, Gabriel Sturgeon e Alana Sturgeon contra Condor Flugdienst GmbH (C-402/07) e Stefan Böck e Cornelia Lepuschitz contra Air France SA(C-432/07). Colectânea da Jurisprudência 2009, p. I-10923. Luxemburgo, 19 nov. 2009.

EUROPEAN COMISSION, Air passengers' rights. Special Eurobarometer 319. Dez. 2009. Disponível em: <http://ec.europa.eu/public_opinion/archives/ebs/ebs_319_en.pdf >. Acesso em: 07 out. 2010.

FAHRGASTRECHTE: Buspassagiere gleichgestellt. EU-Nachrichten. n. 6, p. 3, Alemanha, 17 fev. 2011. Disponível em: <http://ec.europa.eu/deutschland/pdf/eu_nachrichten/eu-nachr.6_2011web. pdf $>$. Acesso em: 21 fev. 2011.

POLLOCK, Ian. Air delay compensation claims suspended by High Court. British Broadcasting Corporation (BBC). 17 ago.2010. Disponívelem:<http://www.bbc.co.uk/news/business-10991631>. 